\title{
Predicting biological variation using a simple morphometric marker in the sedentary marine invertebrate Haliotis rubra
}

\author{
T. Saunders ${ }^{1,2, *}$, S. Mayfield ${ }^{1}$ \\ ${ }^{1}$ South Australian Research and Development Institute (SARDI) Aquatic Sciences, PO Box 120, Henley Beach, \\ South Australia 5022, Australia \\ ${ }^{2}$ Southern Seas Ecology Laboratories, DP418, School of Earth and Environmental Sciences, The University of Adelaide, \\ Adelaide, South Australia 5005, Australia
}

\begin{abstract}
Many sedentary marine invertebrates have a fine-scale $(100 \mathrm{~s} \mathrm{~m})$ population structure that complicates their conservation and management. This is a consequence of the limited information on the boundaries between component populations and the biological variability among them. Blacklip abalone Haliotis rubra form discrete populations, many of which are 'stunted' with individuals reaching a maximum length less than those in adjacent areas. In the present study, we obtained information on the growth, size at maturity and fecundity of $H$. rubra from stunted and 'non-stunted' populations spread across broad $(10 \mathrm{~s} \mathrm{~km})$ and fine $(100 \mathrm{~s} \mathrm{~m})$ spatial scales. Relationships between each of these key population parameters and a simple 'morphometric marker' based on the relationship between shell length and shell height were also examined. Variation in broad-scale growth and size at maturity could primarily be attributed to differences between stunted and non-stunted sites. Within the stunted site, growth and size at maturity were substantially different over distances $>150 \mathrm{~m}$. However, within the non-stunted site these parameters tended to be similar across $1000 \mathrm{~m}$. While the lowest fecundities tended to be in the stunted sites, there was significant overlap among all sites. These spatial patterns in biology were highly correlated with the spatial variability observed in a simple morphometric marker. These results suggest that this morphometric marker can be used as a tool for the spatial management of abalone fisheries by cheaply inferring key biological parameters for individual populations and identifing the boundaries among these based on these differences.
\end{abstract}

KEY WORDS: Biological variation · Morphometric marker · Population boundaries · Spatial management

\section{INTRODUCTION}

It is becoming increasingly evident that many sedentary marine invertebrates demonstrate fine-scale population structure across their range (Strathmann et al. 2002, Orensanz et al. 2005). These individual populations are isolated from conspecifics by reproduction and migration (Berryman 2002) and often vary in their life-history parameters, typically as a consequence of environmental variability (McShane et al. 1988, Orensanz \& Jamieson 1995, Steffani \& Branch 2003, Oren- sanz et al. 2005). While this variability has long been recognised, the spatial scale at which it exists is poorly understood, due to biological data being typically collected from study sites that inadequately represent the variation that occurs across the distribution of the species (Prince 2005). The lack of appropriate data to inform marine scientists and managers has resulted in many of these species becoming serially depleted across their range, with stock collapses occurring in some extreme cases (Tegner et al. 1996, Perry et al. 2002, Orensanz et al. 2005). Thus, while there is a clear 
need to acquire information on the biological variability among separate populations, this process has been restricted by the high costs and difficulties of collecting these data across the required range of spatial scales (Prince 2005).

The collection of morphometric data may offer a cost-effective alternative for inferring key biological parameters for individual populations. This is a result of patterns in morphometric variation reflecting differences in growth, maturation rates and fecundity, as body form is a product of ontogeny (Begg et al. 1999, Cadrin 2005). For example, individuals in populations characterised by slower growth tend to be smaller in body form, mature at smaller sizes and produce less eggs compared to those in populations with faster growth (Campbell \& Ming 2003, Campbell et al. 2003). If biological variability can be linked to a simple morphometric measure, inferring the biology of a species at appropriate spatial scales, using morphological variability as a surrogate becomes practicable. In addition, these relationships enable spatial variability in morphology to be used to identify separate populations of these species (Cadrin \& Silva 2005, Saunders et al. 2008) based on their different biological characteristics. While this approach has been commonly used in teleosts (Worthington et al. 1995b, Berg et al. 2005, Cadrin \& Silva 2005), it can be applied to sedentary marine invertebrates that have easily measurable, hard body parts that reflect their ontogenetic history. Although these morphological characteristics may be environmentally induced (Swain \& Foote 1999, Alunno-Bruscia et al. 2001, Swain et al. 2005), the highly localised populations formed by sedentary invertebrates with limited adult movement and larval dispersal are likely to exist at similar scales to this environmental variation.

Abalone (genus Haliotis) are a typical sedentary invertebrate species, having numerous discrete populations across their range (Prince 2005, Morgan \& Shepherd 2006) that often differ in their biology and morphology (McShane et al. 1988, Worthington et al. 1995a, Worthington \& Andrew 1997, Tarbath 2003). This variability commonly results in the presence of socalled 'stunted' areas of abalone that have a slower growth rate and/or a smaller maximum length compared to adjacent populations (Nash 1992, Wells \& Mulvay 1995). Stunted populations typically form dense aggregations in sheltered areas with lower wave exposure (McShane \& Naylor 1995). It is suggested that abalone in these protected areas grow more slowly, mature at smaller sizes and produce fewer eggs compared to individuals in more exposed habitats (Shepherd et al. 1991, Wells \& Mulvay 1995, Worthington \& Andrew 1997, Campbell et al. 2003). This variability is considered to be primarily a result of lower water movement providing less food in the form of drift algae (Day \& Fleming 1992, Shepherd \& Steinberg 1992, McShane \& Naylor 1995). However, densitydependent processes, or genetic variability, may also contribute to relatively lower rates of growth in stunted areas, compared to other fished populations (Emmett \& Jamieson 1988, Dixon \& Day 2004).

The current broad-scale (100 to $1000 \mathrm{~km}$, McShane et al. 1994a) management of most abalone fisheries fails to account for the finer-scale variability in their population structure, leaving fast-growing populations prone to overfishing and slower-growing populations underutilised (Strathmann et al. 2002, Prince 2005). In response to this localised variability, the spatial scale of management in Australian abalone fisheries has decreased substantially over recent years. Notably, in the Southern Zone of the South Australian abalone fishery (SZ), separately managed, 'fish-down' areas (FDAs), within which the abalone populations are considered stunted, were introduced between 1989 and 1994. Despite these attempts to reduce the spatial scale of management, it is widely acknowledged that the current management areas still encompass numerous populations of abalone that vary in their life-history parameters. To overcome this challenge, stakeholders in the Victorian Western Zone abalone fishery use a qualitative assessment of the shape (flat or domed) and appearance (i.e. clean or fouled) of shells from commercial catches to aid reef-specific assessment (J. Prince pers. comm.). This has led to increasingly complex spatial management of the resource, with current management arrangements including reefspecific catch limits and minimum legal lengths. However, these assessments of shell shape and appearance need to be calibrated with key biological parameters to ensure that individual populations of abalone are being managed on the basis of their biological characteristics.

Obtaining biological information for individual populations of abalone is unlikely to be achievable by traditional research methods, given the high costs of conducting tag-recapture and reproductive studies across the scale of current fisheries. However, the substantial spatial variation in abalone morphology (Breen \& Adkins 1982, McShane et al. 1994b, Worthington et al. 1995a, Saunders et al. 2008) may offer a proxy through which biological variability among populations can be inferred. For example, Saunders et al. (2008) identified a simple 'morphometric marker', based on the ratio of shell length to shell height (SL:SH ratio), that was able to differentiate between stunted and 'non-stunted' populations in the SZ. The authors suggest that the populations formed by the limited dispersal of abalone larvae were likely to exist at similar spatial scales to the variability observed in the SL:SH 
ratio. Consequently, linking this simple measure to key biological parameters has the potential to enhance the utility of the morphometric marker as a tool to support finer-scale spatial management of abalone fisheries.

In the present study, we investigated the spatial variability in the growth, size at maturity and fecundity among populations of the blacklip abalone Haliotis rubra, hereafter referred to as blacklip, in the SZ. This was achieved by collecting biological information from stunted and non-stunted sites at broad $(10 \mathrm{~s} \mathrm{~km})$ and fine $(100 \mathrm{~s} \mathrm{~m})$ spatial scales within this fishery. Further, to assess whether spatial variation in morphology was reflected in the biological variation, we examined the strength of the relationships between key biological parameters and a simple morphometric marker (Saunders et al. 2008). This enabled evaluation of the utility of this morphometric marker to infer biological characteristics among blacklip populations.

\section{MATERIALS AND METHODS}

Study site. The present study was conducted in the SZ, which includes all coastal waters of South Australia east of Meridian $139^{\circ} \mathrm{E}$, with the exception of the Coorong and waters inside the Murray River mouth. Data to evaluate the spatial variation in rate of growth, size at maturity and fecundity were obtained from 8 sites: Gerloffs Bay (GB), Ringwood Reef (RR), Acis Reef (AR), Red Rock Bay (RB), Salmon Hole (SH), Number 2 Rocks (No2), Middle Point (MP) and Cape Northumberland $(\mathrm{CN})$ distributed along $\sim 100 \mathrm{~km}$ of coastline. These were the same sites used in Saunders et al. (2008), and the morphometric data from that study revealed that the first 4 sites contained stunted blacklip while the latter 4 contained non-stunted blacklip (Fig. 1). Using these sites allowed for the direct comparison between spatial patterns in blacklip biology and morphology. To assess finer-scale patterns in blacklip biological parameters, GB and MP were resampled in conjunction with the collection of additional samples from sub-sites located ca. 150 (GB150, MP150), 400 (GB400, MP400) and $1000 \mathrm{~m}$ (GB1000, MP1000) from each of the 2 sites (see insets, Fig. 1). GB and MP were chosen for re-sampling as blacklip from these sites showed biological traits that were typical of stunted and non-stunted populations, respectively. The sub-sites were determined by moving the prescribed distance along a randomly selected compass bearing from the original site, whereupon divers were deployed to locate the nearest aggregation of blacklip.

Growth. Between 368 (SH) and 404 (RR) blacklip were tagged at each of the 8 broad-scale sites between November 2004 and January 2005. This process required that they be removed from the water to tag

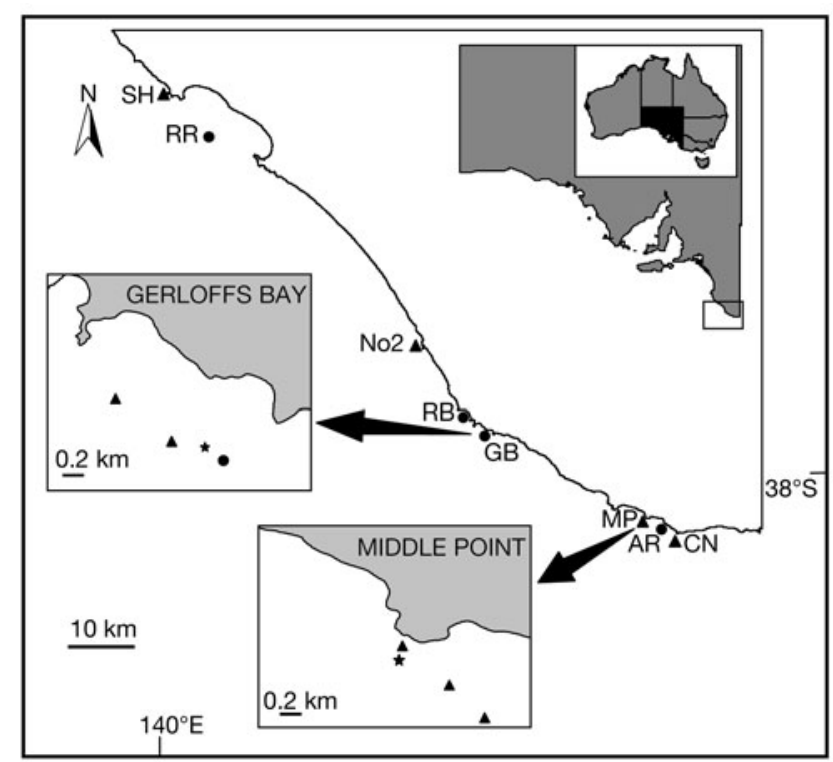

Fig. 1. Study area with the locations of the broad-scale sites: Salmon Hole (SH), Ringwood Reef (RR), Number 2 Rocks (No2), Red Rock Bay (RB), Gerloffs Bay (GB), Middle Point (MP), Acis Reef (AR) and Cape Northumberland (CN). Inset maps show the location of the sub-sites within GB and MP. $\star$ :

broad-scale sites; $\mathbf{\Delta}$ : 'non-stunted' and $\bullet$ : 'stunted' sites

and measure the length of individuals to the nearest $0.5 \mathrm{~mm}$ before they were replaced in the area from where they were collected. Individuals were collected in a haphazard manner to obtain a representative sample of the size range present in each site. Small $(12 \mathrm{~mm})$, individually numbered, plastic disc tags were attached to blacklip by fixing a nylon rivet to the proximal pore hole of each shell (Prince 1991). These individuals were then recaptured and re-measured for SL during January and February 2006. Recaptures from the GB and MP sites were returned to the site from which they were recaptured so that growth data could be collected at these sites during the same time period as the sub-sites. At the sub-sites, between 158 (GB1000) and 288 (GB150) blacklip were tagged and measured as described above between January and May 2006 and were recaptured and re-measured between November 2006 and April 2007 (Table 1).

Size at maturity. Between 120 (SH) and 256 (GB) blacklip (>30 mm SL) were collected by SCUBA divers from the broad-scale sites between October 2004 and February 2005. Blacklip show high levels of gonad present between October and April in the SZ (Mayfield et al. 2002), so the blacklip sampled during the present study should not have their size at maturity skewed to higher size classes as a result of having recently spawned. In addition, between 131 (MP150) and 187 (GB150) blacklip were collected between December 
Table 1. Tagging data used to determine growth and collection data used to determine the size at maturity and fecundity of blacklip at all sites. Gerloffs Bay 1 and Middle Point 1 indicate the broad-scale sites that were re-sampled along with the sub-sites. Dates: dd/mm/yy

\begin{tabular}{|c|c|c|c|c|c|c|c|c|c|}
\hline \multirow[t]{2}{*}{ Site } & \multicolumn{6}{|c|}{ - Tagging data $\longleftarrow$} & \multicolumn{3}{|c|}{ Collection data } \\
\hline & $\begin{array}{l}\text { Date } \\
\text { tagged }\end{array}$ & $\begin{array}{r}\text { No. S } \\
\text { tagged }\end{array}$ & $\begin{array}{l}\text { Size range } \\
\text { tagged }\end{array}$ & $\begin{array}{l}\text { Date re- } \\
\text { captured }\end{array}$ & $\begin{array}{l}\text { No. re- } \\
\text { captured }\end{array}$ & $\begin{array}{l}\text { Size range } \\
\text { recaptured }\end{array}$ & $\begin{array}{c}\text { Date } \\
\text { collected }\end{array}$ & $\begin{array}{l}\text { No. } \\
\text { ollected }\end{array}$ & $\begin{array}{l}\text { Size range } \\
\text { collected }\end{array}$ \\
\hline Acis Reef (AR) & $11 / 11 / 04$ & 398 & $34-148$ & $21 / 01 / 06$ & 65 & $67-148$ & $31 / 10 / 04$ & 215 & $15-147$ \\
\hline Cape Northumberland (CN) & $26 / 11 / 04$ & 396 & $21-148$ & $06 / 02 / 06$ & 75 & $60-148$ & $31 / 10 / 04$ & 173 & $39-159$ \\
\hline Gerloffs Bay (GB) & $29 / 01 / 05$ & 402 & $28-124$ & $05 / 02 / 06$ & 58 & $41-124$ & $11 / 02 / 05$ & 256 & $27-122$ \\
\hline Middle Point (MP) & $10 / 11 / 04$ & 399 & $38-167$ & $21 / 01 / 06$ & 59 & $38-167$ & $31 / 10 / 04$ & 128 & $30-170$ \\
\hline Number 2 Rocks (No2) & $27 / 11 / 04$ & 398 & $41-164$ & $20 / 01 / 06$ & 97 & $75-166$ & $27 / 11 / 04$ & 168 & $11-158$ \\
\hline Red rock Bay (RB) & $03 / 12 / 04$ & 397 & $60-150$ & $20 / 01 / 06$ & 74 & $78-150$ & $28 / 11 / 04$ & 131 & $28-148$ \\
\hline Ringwood Reef (RR) & $25 / 11 / 04$ & 404 & $36-147$ & $19 / 01 / 06$ & 63 & $55-147$ & $17 / 10 / 04$ & 203 & $37-141$ \\
\hline Salmon Hole (SH) & $13 / 12 / 04$ & 368 & $54-181$ & $19 / 01 / 06$ & 76 & $85-181$ & $17 / 10 / 04$ & 120 & $51-167$ \\
\hline Gerloffs Bay 1 (GB1) & $29 / 01 / 06$ & 58 & $41-124$ & $22 / 11 / 06$ & 39 & $36-112$ & $04 / 01 / 07$ & 153 & $49-124$ \\
\hline Gerloffs Bay 150 (GB150) & $16 / 05 / 06$ & 288 & $37-142$ & $16 / 04 / 07$ & 34 & $37-120$ & $04 / 01 / 07$ & 187 & $53-130$ \\
\hline Gerloffs Bay 400 (GB400) & $17 / 05 / 06$ & 179 & $63-160$ & $25 / 04 / 07$ & 45 & $63-149$ & $10 / 01 / 07$ & 162 & $49-160$ \\
\hline Gerloffs Bay 1000 (GB1000) & $16 / 05 / 06$ & 158 & $41-186$ & $16 / 04 / 07$ & 32 & $53-160$ & $10 / 01 / 07$ & 168 & $48-145$ \\
\hline Middle Point 1 (MP1) & $21 / 01 / 06$ & 59 & $75-156$ & $13 / 04 / 07$ & 28 & $63-154$ & $10 / 12 / 06$ & 135 & $48-156$ \\
\hline Middle Point 150 (MP150) & $26 / 04 / 06$ & 207 & $53-160$ & $13 / 04 / 07$ & 70 & $61-161$ & $10 / 12 / 06$ & 131 & $44-150$ \\
\hline Middle Point 400 (MP400) & $27 / 04 / 06$ & 201 & $49-155$ & $14 / 04 / 07$ & 35 & $57-140$ & $10 / 12 / 06$ & 138 & $59-153$ \\
\hline Middle Point 1000 (MP1000) & $26 / 04 / 06$ & 209 & $40-152$ & $13 / 04 / 07$ & 51 & $56-141$ & $10 / 12 / 06$ & 161 & $50-158$ \\
\hline
\end{tabular}

2006 and January 2007 from the sub-sites within GB and MP (Table 1). Each blacklip was measured and the reproductive state (immature, male or female) determined macroscopically, based on gonad colour (immature-brown, male-creamy, and female-pale green; Shepherd \& Laws 1974).

Fecundity. The entire visceral mass of ca. 30 mature female blacklip were retained from the size-atmaturity samples from all sites. Individuals ranged in size from 55 to $157 \mathrm{~mm}$ SL. To preserve the visceral mass for subsequent egg counting, each sample was labelled and preserved in $100 \%$ ethanol for at least $1 \mathrm{mo}$.

Following preservation, the ovary was excised from the visceral mass and weighed to the nearest $0.01 \mathrm{~g}$. Estimates of the no. eggs $\mathrm{g}^{-1}$ of ovary were obtained from 3 sub-samples taken from 3 regions of the gonad (tip of the conical appendage, top of the body whorl, and anterior gonad; after Wells \& Keesing 1989). Subsample wet weights ranged from 0.4 to $2.5 \mathrm{mg}$. Each sub-sample was separated, and the eggs flushed into a plankton-counting chamber with $70 \%$ ethanol and counted using a dissecting microscope at $40 \times$ magnification. The total number of eggs for each blacklip was calculated by multiplying the average no. of eggs $\mathrm{g}^{-1}$ of ovary by the total weight of the ovary.

Data analysis. To test for differences in rates of growth among sites, an analysis of covariance (ANCOVA) was carried out on the regression slopes of annual growth rate against length at tagging.

The percentage of mature blacklip was determined for individual $5 \mathrm{~mm}$ size classes. These data were fitted to a 2 parameter logistic curve (after Schnute \& Richards 1990) of the form:

$$
\mathrm{P}(L)=\left(1+\mathrm{e}^{-\left(L-L_{50}\right) / \delta}\right)^{-1}
$$

Where $\mathrm{P}(L)$ represents the proportion of mature blacklip from length class $L, L_{50}$ the length at $50 \%$ maturity and $\delta$ the steepness of the ogive. The model parameters were estimated by minimising the negative binomial likelihoods. The confidence intervals for $L_{50}$ were determined using profile likelihood methods (Haddon 2001). Likelihood ratio tests were used to test for differences in $L_{50}$ among sites.

Egg no. ind. ${ }^{-1}$ was log transformed and differences among the slopes and $y$-intercepts of the resultant linear relationships $\left(\log\right.$ egg no. $=m[\mathrm{SL}]+c_{\text {, }}$ where $m$ is the slope and $c$ the intercept on the $y$-axis) were investigated using ANCOVA. Site was a random factor and SL a covariate for these analyses.

Given the assumption of ANCOVA that the covariate is similarly distributed between treatments for each analysis (Quinn \& Keough 2002), data were truncated to examine the robustness of the test. Truncating the growth or log transformed fecundity data did not alter the significance of the test, so all data were retained in the analyses. To determine where the significant differences lay between factors, Student's $t$-tests on adjusted means were calculated for each combination of factors with a sequential Bonferonni adjustment of significance levels to correct for multiple testing (Quinn \& Keough 2002).

Each biological parameter (residuals of growth, $L_{50}$ and residuals of fecundity) was plotted against the 
average SL:SH ratio for each of the broad-scale and sub-site samples. The average growth residuals were calculated by using multiple linear regression for the 8 broad-scale sites. The residuals from this analysis indicated whether a shell was longer or shorter than expected compared to the average growth relationship. Residuals were calculated in the same way for the sub-sites. This residual analysis was used in a similar way on the log transformed fecundity relationship among sites. The maximum likelihood estimates calculated for $L_{50}$ above were used in these plots. Relationships among these variables were investigated through Pearson's correlation analyses.

\section{RESULTS}

\section{Growth}

There was a significant linear relationship between SL at tagging and rate of growth at all sites, with larger individuals growing more slowly compared to smaller ones (Table 2, Figs. 2 \& 3). There was significant variation among the broad-scale sites (ANCOVA, $F_{7,533}=$ $20.05, \mathrm{p}<0.0001)$. This variation was primarily a result of blacklip in the non-stunted sites (CN, MP, No2 and $\mathrm{SH})$ having significantly higher rates of growth when compared to those in stunted sites (AR, GB, RB and RR; Fig. 2). Furthermore, among the non-stunted sites, blacklip in No2 and SH had significantly faster rates of growth compared to $\mathrm{CN}$ and MP (Fig. 2). There was

Table 2. Sample size (n), correlation coefficient (r) from the relationship between blacklip shell length (SL) at tagging and annual growth rate for all sites. Values for $a$ and $b$ represent the constants for this linear relationship. For site definitions see Table 1. $\mathrm{p}<0.001$ for all sites

\begin{tabular}{|lcccc|}
\hline Site & $\mathrm{n}$ & $\mathrm{a}$ & $\mathrm{b}$ & $\mathrm{r}$ \\
\hline AR & 62 & 0.212 & 27.12 & -0.921 \\
CN & 75 & 0.217 & 30.07 & -0.885 \\
GB & 58 & 0.157 & 18.84 & -0.855 \\
MP & 59 & 0.225 & 32.01 & -0.904 \\
No2 & 82 & 0.225 & 36.01 & -0.845 \\
RB & 74 & 0.184 & 24.27 & -0.858 \\
RR & 63 & 0.191 & 24.49 & -0.916 \\
SH & 76 & 0.257 & 39.98 & -0.898 \\
GB1 & 39 & 0.114 & 15.61 & -0.527 \\
GB150 & 31 & 0.060 & 11.98 & -0.381 \\
GB400 & 44 & 0.239 & 34.75 & -0.813 \\
GB1000 & 33 & 0.169 & 28.26 & -0.669 \\
MP1 & 28 & 0.225 & 31.34 & -0.937 \\
MP150 & 70 & 0.333 & 47.66 & -0.898 \\
MP400 & 35 & 0.296 & 39.85 & -0.816 \\
MP1000 & 51 & 0.268 & 38.12 & -0.784 \\
& & & & \\
\hline
\end{tabular}

also significant variation among the blacklip tagged within GB (ANCOVA, $F_{3,145}=8.84, \mathrm{p}<0.0001$ ) and MP (ANCOVA, $F_{3,179}=22.9, \mathrm{p}<0.0001$ ). Multiple comparisons revealed that blacklip in GB, GB150 and MP1000 had significantly slower rates of growth compared to the other sites (Fig. 3).

\section{Size at maturity}

Among the broad-scale sites, the likelihood ratio test revealed that SL at $50 \%$ maturity $\left(L_{50}\right)$ was generally significantly lower for blacklip in stunted compared to non-stunted sites (Fig. 4). The exception was RB which had a similar $L_{50}$ compared to those for most of the nonstunted sites (Fig. 4). In addition, SH had a significantly higher $L_{50}$ compared to all of the other sites (Fig. 4). There were also differences in $L_{50}$ within GB as a result of GB and GB150 having significantly lower $L_{50}$ compared to the other sites (Fig. 5). At MP, $L_{50}$ at MP1000 was significantly lower compared to the rest of the sites in this area (Fig. 5).

\section{Fecundity}

Samples among the broad-scale sites showed significant variability in fecundity (ANCOVA, $F_{7,254}=2.31$, $\mathrm{p}<0.03)$. However, the multiple comparisons revealed that these were a result of blacklip within GB and RB having significantly lower fecundity compared to the other sites rather than differences between stunted and non-stunted sites (Fig. 6). There were also significant differences in the fecundity of blacklip within GB (ANCOVA, $\left.F_{3,82}=6.00, \mathrm{p}<0.001\right)$ and MP (ANCOVA, $F_{3,80}=4.41, \mathrm{p}<0.01$ ). Multiple comparisons revealed that blacklip in GB, GB150 and MP1000 had significantly lower fecundity compared to the other sites (Fig. 7).

\section{Relation of biology to morphology}

The correlation analysis revealed significant positive relationships between the SL:SH ratio and growth (broad-scale sites: $\mathrm{r}^{2}{ }_{7}=0.646, \mathrm{p}<0.01$; sub-sites: $\mathrm{r}^{2}{ }_{7}=$ $0.753, \mathrm{p}<0.005$ ), $L_{50}$ (broad-scale sites: $\mathrm{r}^{2}{ }_{7}=0.579, \mathrm{p}<$ 0.02; sub-sites: $\mathrm{r}_{7}^{2}=0.856, \mathrm{p}<0.001$ ) and fecundity (broad-scale sites: $\mathrm{r}^{2}{ }_{7}=0.453, \mathrm{p}<0.05$; sub-sites: $\mathrm{r}^{2}=$ $0.514, \mathrm{p}<0.05$; Fig. 8). Furthermore, when the data from the broad-scale and sub-sites were combined, there were significant correlations between the SL:SH ratio and each of the biological parameters (growth: $\mathrm{r}_{15}{ }_{15}=0.682, \mathrm{p}<0.001 ; L_{50}: \mathrm{r}_{15}^{2}=0.651, \mathrm{p}<0.001$; fecundity: $\mathrm{r}^{2}{ }_{15}=0.419, \mathrm{p}=0.005$; Fig. 8). 

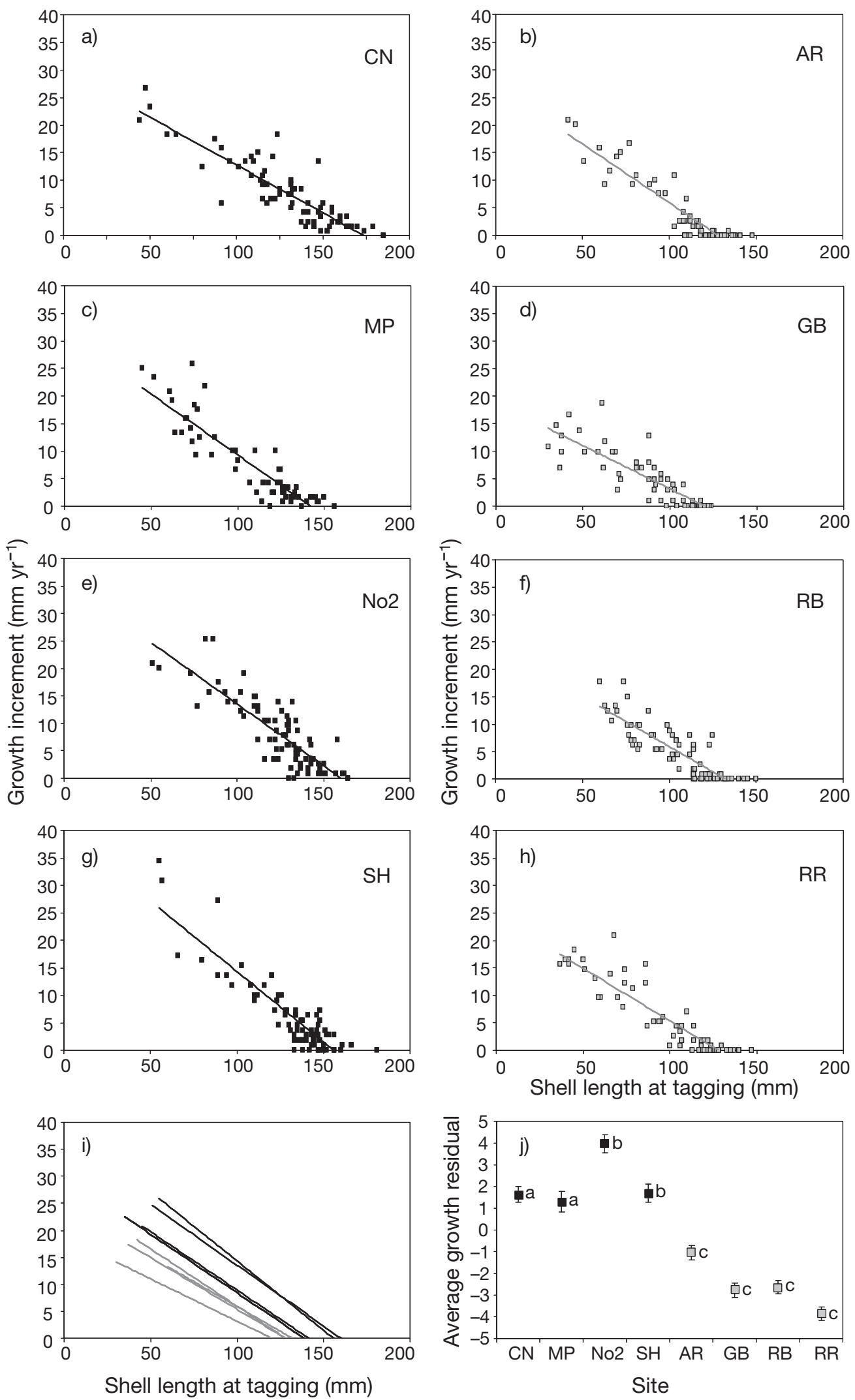

Fig. 2. (a-h) Relationship between shell length (SL) at tagging and growth increment for blacklip at the broad-scale sites. (i) The trend lines for each of these relationships and (j) the average growth residuals for all sites. Letters in (j) indicate similar groups classified by the multiple comparisons. Black and grey symbols indicate 'non-stunted' and 'stunted' sites, respectively. Error bars 

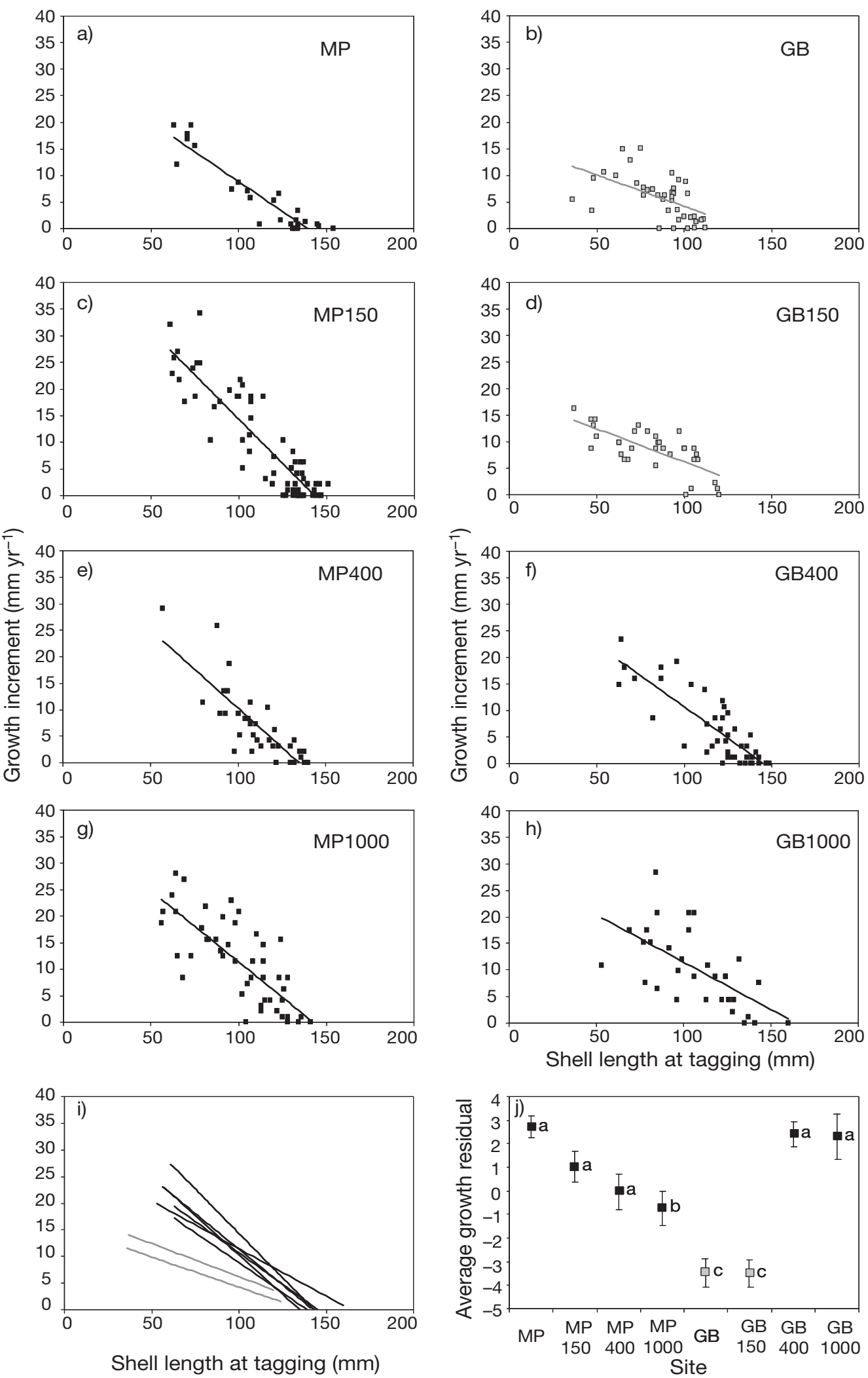

Fig. 3. (a-h) Relationship between shell length (SL) at tagging and growth increment for blacklip at the MP and GB broad-scale sites and sub-sites. (i) The trend lines for each of these relationships and (j) the average growth residuals for all sites. Letters in (j) indicate similar groups classified by the multiple comparisons. Black and grey symbols indicate 'non-stunted' and 'stunted' sites, respectively. Error bars indicate $\pm 1 \mathrm{SE}$ 

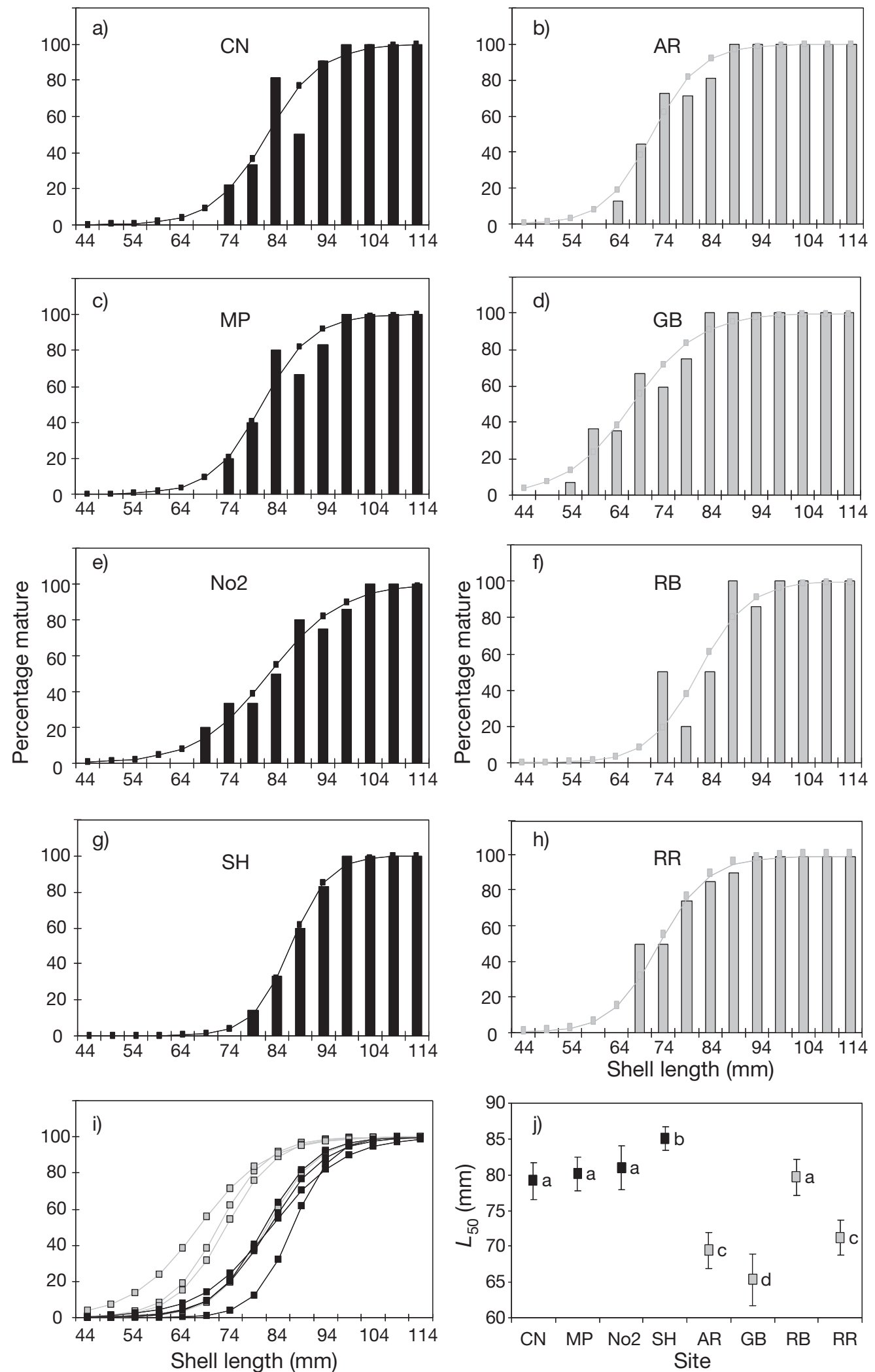

Fig. 4. (a-h) Percentage blacklip mature within each size class at the broad-scale sites. (i) The trend lines for each of these relationships and (j) the estimates of $L_{50}$ for all sites. Letters in (j) indicate similar groups classified by the likelihood ratio test. Black and grey symbols indicate 'non-stunted' and 'stunted' sites, respectively. Error bars indicate 95\% CI 

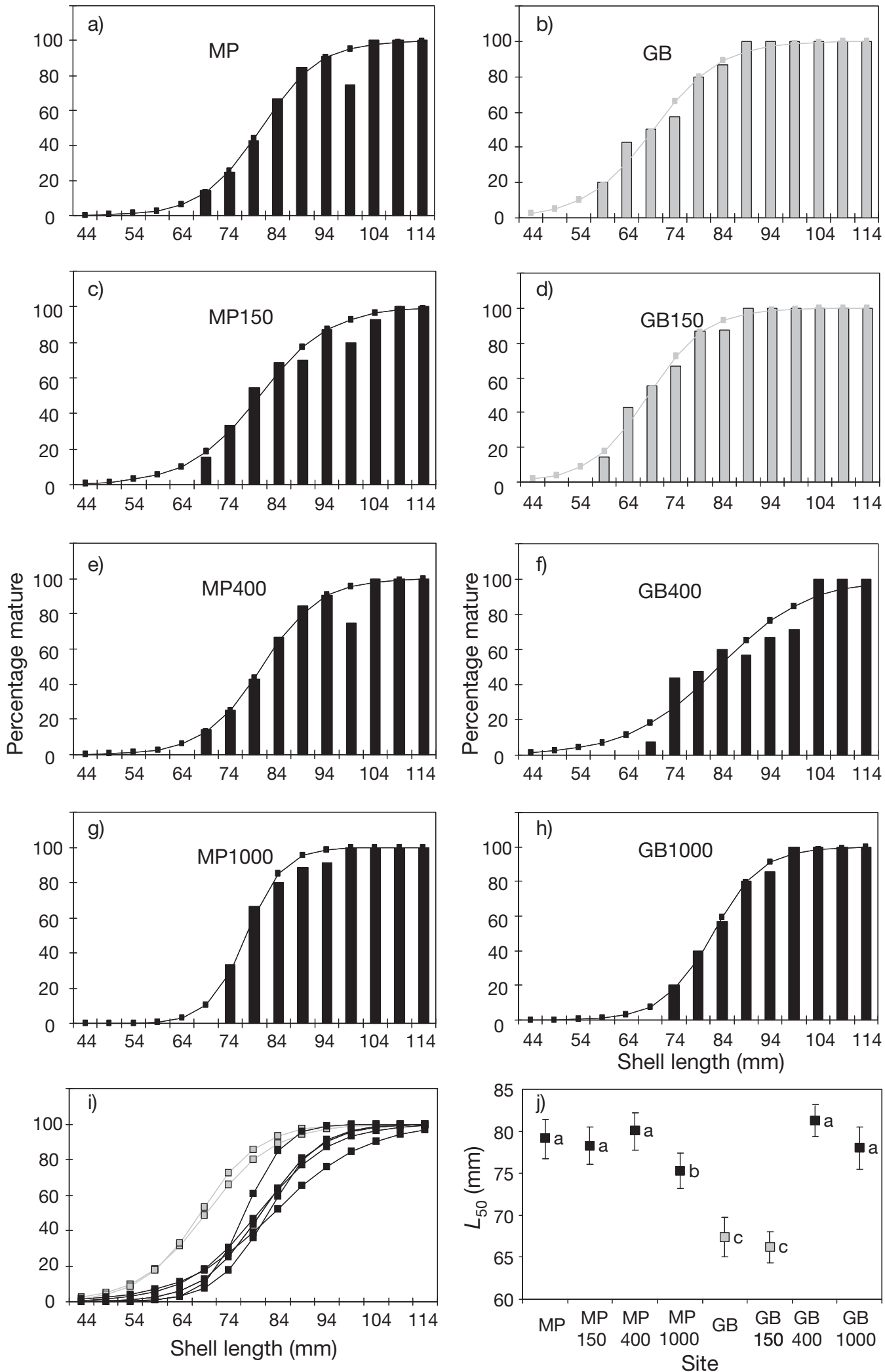

Fig. 5. (a-h) Percentage blacklip mature within each size class at the MP and GB broad-scale sites and sub-sites. (i) The trend lines for each of these relationships and (j) the estimates of $L_{50}$ for all sites. Letters in (j) indicate similar groups classified by the likelihood ratio test. Black and grey symbols indicate 'non-stunted' and 'stunted' sites, respectively. Error bars indicate $95 \% \mathrm{CI}$ 

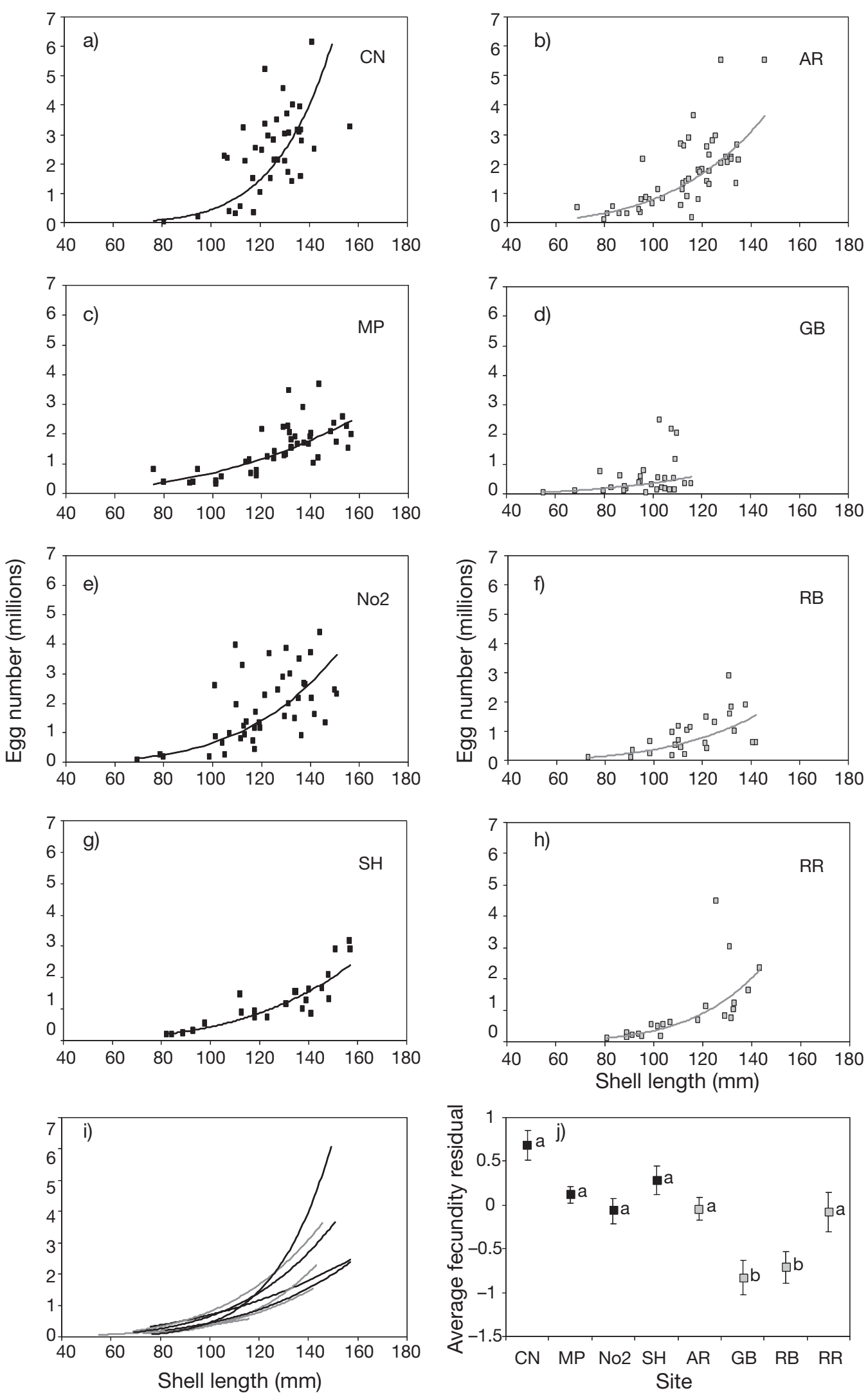

Fig. 6. (a-h) Relationship between no. eggs ind.$^{-1}$ and shell length (SL) for blacklip at the broad-scale sites. (i) The trend lines for each of these relationships and (j) the average fecundity residuals for all sites. Letters in (j) indicate similar groups classified by the multiple comparisons. Black and grey symbols indicate 'non-stunted' and 'stunted' sites, respectively. Error bars indicate \pm 1 SE 

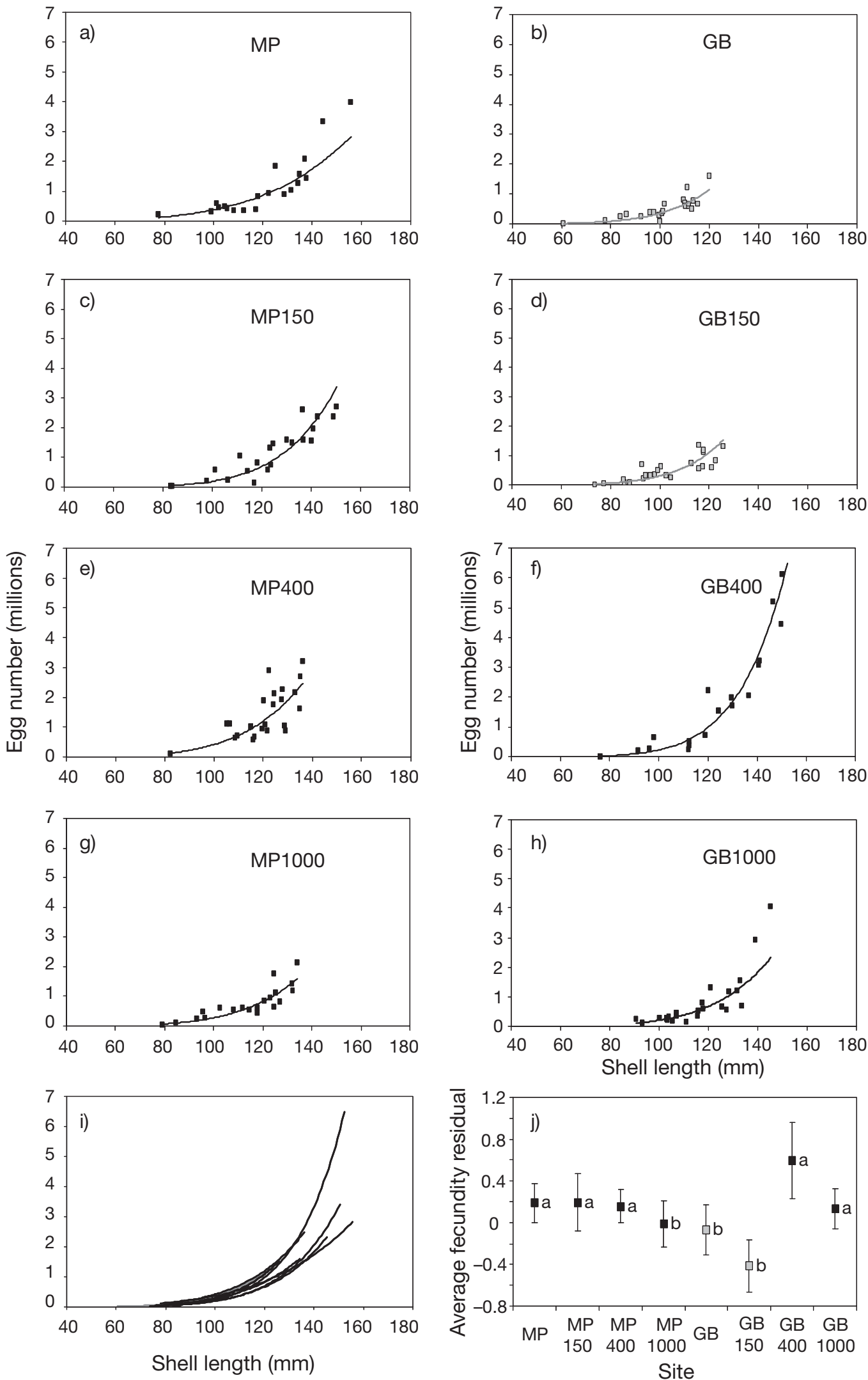

Fig. 7. (a-h) Relationship between no. eggs ind.$^{-1}$ and shell length (SL) for blacklip at the MP and GB broad-scale sites and subsites. (i) The trend lines for each of these relationships and (j) the average fecundity residuals for all sites. Letters in (j) indicate similar groups classified by the multiple comparisons. Black and grey symbols indicate 'non-stunted' and 'stunted' sites, respectively. Error bars indicate $\pm 1 \mathrm{SE}$ 

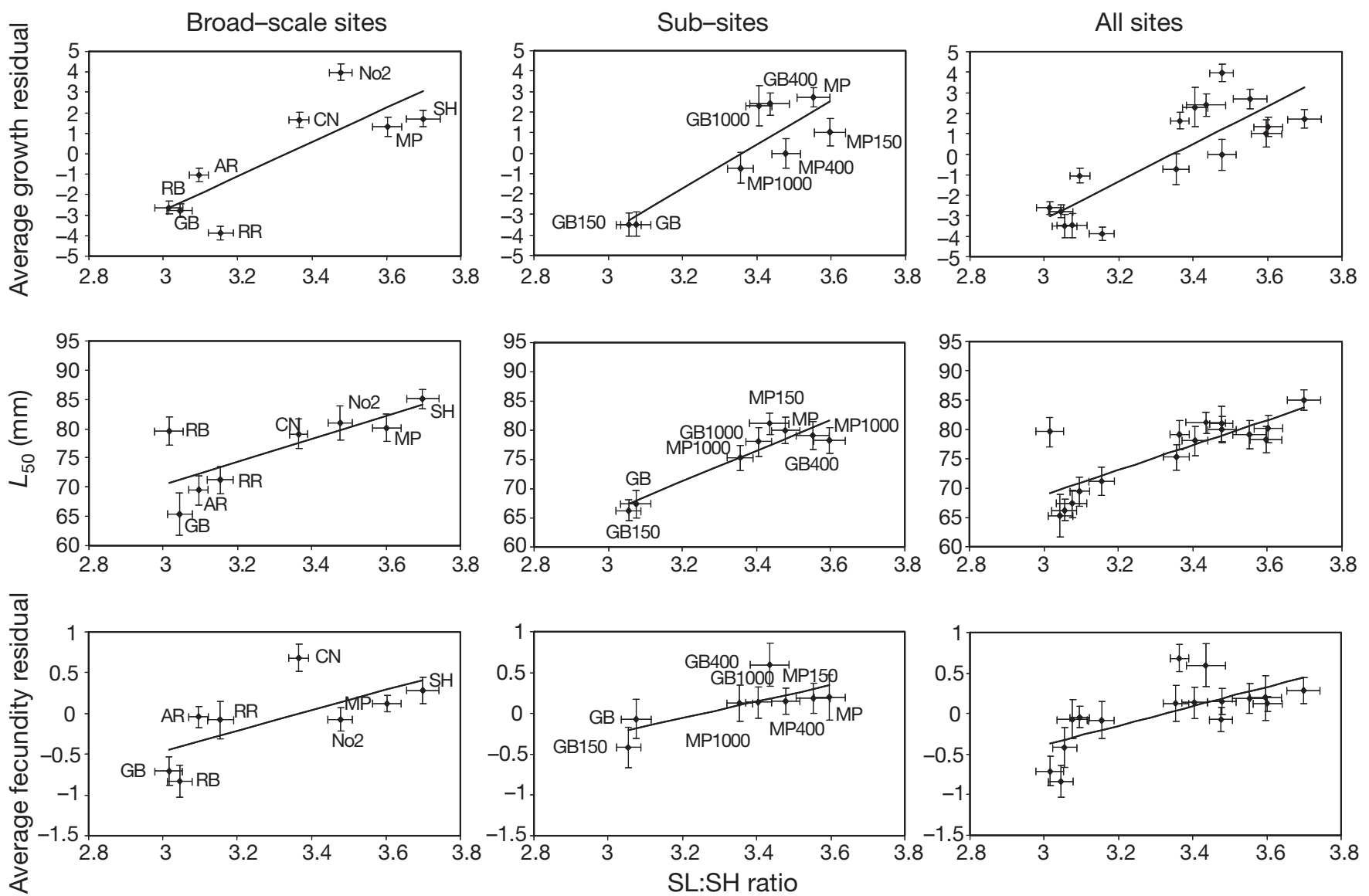

Fig. 8. Relationship between the SL:SH ratio and average growth residuals, estimates of $L_{50}$ and average fecundity residuals for the broad-scale sites, sub-sites and all sites combined. Error bars indicate \pm 1 SE for growth and fecundity residuals and $95 \%$ CI for estimates of $L_{50}$

\section{DISCUSSION}

The collection of information on growth, size at maturity and fecundity across both broad $(10 \mathrm{~s} \mathrm{~km})$ and fine $(100 \mathrm{~s} \mathrm{~m})$ spatial scales demonstrated that these parameters vary at both of these scales. Moreover, we were able to demonstrate that these parameters were significantly correlated to a simple morphometric marker (Saunders et al. 2008). The spatial variability in the biology of blacklip observed is likely a result of fine-scale spatial variability in environmental factors (Swain et al. 2005). However, the dispersal of blacklip probably only occurs at scales of 10 to $100 \mathrm{~s}$ m (Prince et al. 1987). Therefore, populations formed under these conditions exist at very fine spatial scales (Temby et al. 2007) and would be similar to that at which environmental variability operates (Saunders et al. 2008). Consequently, the morphometric marker could provide a valuable tool to aid fine-scale management of abalone fisheries by inferring the key biological parameters of individual populations and through using this information to discriminate among these.
The substantial spatial variation in growth that we observed for blacklip in the SZ appears to be characteristic of abalone populations worldwide (McShane et al. 1988, Day \& Fleming 1992, Worthington et al. 1995a). Differences in growth among the broad-scale sites were primarily determined by the site being within a stunted or non-stunted area. Within GB, the stunted pattern of growth was only observed within $400 \mathrm{~m}$ of the original site; the sites beyond this distance had significantly higher growth rates that were similar to those in the non-stunted sites. In contrast, growth patterns of blacklip in MP were consistent across a broader area, to at least $1000 \mathrm{~m}$ from the original site. These differences are likely to be attributed, in part, to blacklip in stunted sites being exposed to lower food availability as a result of less water movement and hence less drift algae compared to non-stunted populations (McShane et al. 1988, Day \& Fleming 1992, Worthington et al. 1995a). Furthermore, higher densities of conspecifics may have also contributed to differences in the rate of growth among sites (Dixon \& Day 2004), as abundances of blacklip were ca. 7 times 
greater within stunted sites compared to those in nonstunted (South Australian Research and Development Institute unpubl. data). In addition to these factors, genetic variability among populations may be influencing the growth of abalone (Worthington et al. 1995a). To delineate how these environmental or genetic factors contribute to this observed spatial variation in growth, reciprocal transplant experiments need to be conducted (Swain \& Foote 1999).

The spatial variability in size at maturity closely matched that observed for growth. At broad spatial scales, sites that contained stunted blacklip generally had a smaller size at maturity compared to those in non-stunted sites. The exception to this was the blacklip in one stunted site (RB) where they grew slowly but matured at a similar size to individuals in the nonstunted sites. Anecdotal evidence from fishers suggests that blacklip in this area grow quickly, but this manifests itself in changes in shell width and height as opposed to length. Importantly, within GB and MP the spatial variability in size at maturity mimicked that for growth. These results are unsurprising as growth rate reflects both individual size at age and the rate at which that size is attained and will affect size/age of maturity for individuals (Begg et al. 1999, Cadrin 2005). Indeed, these patterns in growth and size at maturity are commonly observed in abalone populations in Tasmania (Tarbath 2003), New South Wales (Worthington et al. 1995a), Victoria (McShane et al. 1988) and elsewhere in South Australia (Shepherd \& Hearn 1983). These observations are probably a result of maturity being related to age, with blacklip in stunted areas maturing at the same age, but at a smaller size, compared to those in non-stunted areas (Shepherd \& Laws 1974, Prince et al. 1988, Shepherd et al. 1991, Nash 1992, McShane \& Naylor 1995). However, as we have no data on the age of individual blacklip in the present study, the observation of smaller size at maturity at stunted compared to nonstunted sites may reflect plasticity in the life-history strategy of blacklip among these areas (McAvaney et al. 2004, Naylor et al. 2006).

Among the broad-scale sites, the stunted sites that exhibited the lowest growth rates (GB and RB) all had the lowest levels of fecundity; however, the stunted sites that had slightly higher growth rates tended to have similar levels of fecundity compared to those in the non-stunted sites. Nevertheless, within GB and MP the spatial patterns in fecundity were consistent with those observed for growth and size at maturity. Similar spatial variability in growth and fecundity have been observed, with abalone generally producing fewer eggs in stunted compared to non-stunted areas (Shepherd et al. 1992, Wells \& Mulvay 1995, Campbell et al. 2003). The fact that fecundity was not as tightly linked to growth, when compared to size at maturity, is probably due to the substantial individual variation that was observed in egg-count data in the present study. This variability is most likely caused by the low sample sizes not accounting for the highly variable timing and duration of spawning of blacklip (Shepherd \& Laws 1974). Consequently, at the time of collection all blacklip may have appeared to be fully gravid, despite some individuals having spawned and only having a fraction of their eggs.

The spatial variability in the biology of blacklip we have observed at multiple scales in the SZ was not unexpected, as it has been documented in numerous studies in Australia and elsewhere around the world. However, we have taken the identification of this variability in the SZ three additional steps forward. Firstly, we have demonstrated that growth, size at maturity and fecundity tend to co-vary together across these spatial scales. Previous studies have typically focussed on the spatial variability of these parameters in isolation. Secondly, we were able to identify the scale at which biological variability exists within 2 locations in the SZ. In GB, populations of blacklip that exhibited stunted characteristics (low growth, small size at maturity and low fecundity) were observed to occupy an area of ca. $400 \mathrm{~m}$ compared to $1000 \mathrm{~m}$ for the non-stunted population of blacklip in MP. Thirdly, and most importantly, we have demonstrated that the SL:SH ratio developed previously (Saunders et al. 2008) is highly correlated to key life-history parameters among populations of blacklip at both broad (10s $\mathrm{km}$ ) and fine (100s m) spatial scales. Therefore, even though the biological classifications of the populations we have examined were not always consistent, these strong relationships allow for the biological characteristics of other populations of blacklip to be inferred simply and inexpensively by applying the SL:SH ratio to spatially resolved, commercial-catch samples. These results provide further evidence for the utility of the SL:SH ratio to aid fine-scale management of abalone fisheries. Not only can it provide information on the boundaries of separate populations (Saunders et al. 2008), but it can also be used to estimate the growth, size at maturity and fecundity for any population based on the relationships developed in the present study. Consequently, the assessment of samples from across the SZ fishery will ultimately enable blacklip populations to be mapped, with fine-scale systematic sampling facilitating determination of the boundaries of individual populations within and between these areas. The biological information inferred by the SL:SH ratio could then be used to assign individual populations of blacklip with appropriate size limits that reflect their biological characteristics. 
The present study provides an important step towards practical implementation of fine-scale management strategies for abalone fisheries. Identifying the strong correlation between a simple morphometric marker and estimates of key biological parameters provides a potential tool to infer biological variability among populations of abalone and to separate them on this basis. Obtaining this information by traditional research methods remains challenging due to the high costs of obtaining demographic data at appropriate spatial scales. Thus, use of the morphometric marker provides a simple, cost-effective opportunity to bridge the traditional disconnect between scales of ecological variation and fisheries management. While this approach is particularly pertinent for abalone, given their stock structure and history of sudden collapse, it could also be applied to many other sedentary invertebrates that have fine-scale population structure and easily measurable hard-body parts that reflect their ontogenetic history. Consequently, being able to predict biological variation using a morphometric marker is broadly applicable and can assist with the conservation and management of many marine species.

Acknowledgements. We thank Associate Professor S. Connell, Dr. B. Russell and R. Chick for comments. We also thank A. Hogg for assistance with field and laboratory work, and N. Chambers, S. Coe, P. Hawthorne, M. Hoare and A. Jones for assistance with diving. This research was part of a Fisheries Research and Development Corporation (FRDC) grant (Project Number 2004/019, Principal Investigator S. Mayfield) awarded to SARDI.

\section{LITERATURE CITED}

Alunno-Bruscia M, Bourget E, Fréchette M (2001) Shell allometry and length-mass-density relationship for Mytilus edulis in an experimental food-regulated situation. Mar Ecol Prog Ser 219:177-188

Begg GA, Hare JA, Sheehan DD (1999) The role of life history parameters as indicators of stock structure. Fish Res 43: 141-163

Berg E, Sarvas TH, Harbitz A, Fevolden SE, Salberg AB (2005) Accuracy and precision in stock separation of north-east Arctic and Norwegian coastal cod by otoliths comparing readings, image analyses and a genetic method. Mar Freshw Res 56:753-762

Berryman AA (2002) Population: a central concept for ecology? Oikos 97:439-442

Breen PA, Adkins BE (1982) Observations of abalone populations on the north coast of British Columbia, July 1980. Department of Fisheries and Oceans Resource Services Branch, Report No. 1633, Nanaimo

Cadrin SX (2005) Morphometric landmarks. In: Cadrin SX, Friedland KD, Waldmann JR (eds) Stock identification methods applications in fishery science. Elsevier Academic Press, London, p 153-172

> Cadrin SX, Silva VM (2005) Morphometric variation of yellowtail flounder. ICES J Mar Sci 62:683-694
Campbell A, Ming MD (2003) Maturity and growth of the pacific geoduck clam, Panopea abrupta, in Southern British Columbia, Canada. J Shellfish Res 22:85-90

Campbell A, Lessard J, Jamieson GS (2003) Fecundity and seasonal reproduction of northern abalone, Haliotis kamtschatkana, in Barkley Sound, Canada. J Shellfish Res 22: 811-818

Day RW, Fleming AE (1992) The determinants and measurement of abalone growth. In: Shepherd SA, Tegner MJ, Guzman del Proo SA (eds) Abalone of the world: biology, fisheries and culture. Fishing News Books, Oxford, p 141-168

Dixon CD, Day RW (2004) Growth responses in emergent greenlip abalone to density reductions and translocations. J Shellfish Res 23:1223-1228

Emmett B, Jamieson GS (1988) Transplant of abalone in Barkley Sound, British Columbia. J Shellfish Res 7:117

Haddon M (2001) Modelling and quantitative methods in fisheries. Chapman \& Hall/CRC, Boca Raton, FL

Mayfield S, Saunders T, Jones A, Ward TM (2002) Abalone (Southern Zone). Fishery assessment report to PIRSA Fisheries Policy Group. SARDI Aquatic Sciences, Adelaide

McAvaney LA, Day RW, Dixon CD, Huchette SM (2004) Gonad development in seeded Haliotis laevigata: growth environment determines initial reproductive investment. J Shellfish Res 23:1213-1218

McShane PE, Naylor JR (1995) Small-scale spatial variation in growth, size at maturity, and yield- and egg-per-recruit relations in the New Zealand abalone Haliotis iris. NZ J Mar Freshw Res 29:603-612

McShane PE, Smith MG, Beinssen KHH (1988) Growth and morphometry in abalone (Haliotis rubra Leach) from Victoria. Aust J Mar Freshw Res 39:161-166

McShane PE, Mercer SF, Naylor JR (1994a) Spatial variation and commercial fishing of New Zealand abalone (Haliotis iris and $H$. australis). NZ J Mar Freshw Res 28:345-355

McShane PE, Schiel DR, Mercer SF, Murray T (1994b) Morphometric variation in Haliotis iris (Mollusca, Gastropoda)-analysis of 61 populations. NZ J Mar Freshw Res 28:357-364

Morgan LE, Shepherd SA (2006) Population and spatial structure of 2 common temperate reef herbivores: abalone and sea urchins. In: Kritzer JP, Sale, PF (eds) Marine metapopulations. Elsevier Academic Press, Burlington, p 205-234

Nash WJ (1992) An evaluation of egg-per-recruit analysis as a means of assessing size limits for blacklip abalone (Haliotis rubra) in Tasmania. In: Shepherd SA, Tegner MJ, Guzman del Proo SA (eds) Abalone of the world: biology, fisheries and culture. Fishing News Books, Oxford, p 318-341

Naylor JR, Andrew NL, Kim SW (2006) Demographic variation in the New Zealand abalone Haliotis iris. Mar Freshw Res 57:215-224

Orensanz JM, Jamieson GC (1995) The assessment and management of spatially structured stocks: an overview of the North Pacific Symposium on Invertebrate Stock Assessment and Management. In: Proc NP Symp Invertebr Stock Assess Manage. Can Spec Publ Fish Aquat Sci 125: 441-459

Orensanz JM, Parma AM, Jerez G, Barahona N, Montecinos M, Elias I (2005) What are the key elements for the sustainability of 'S-fisheries'? Insights from South America. Bull Mar Sci 76:527-556

Perry RI, Zhang ZY, Harbo R (2002) Development of the green sea urchin (Strongylocentrotus droebachiensis) fishery in British Columbia, Canada-back from the brink using a precautionary framework. Fish Res 55:253-266

Prince JD (1991) A new technique for tagging abalone. Aust 
J Mar Freshw Res 42:101-106

Prince J (2005) Combating the tyranny of scale for Haliotids: micro-management for microstocks. Bull Mar Sci 76: $557-577$

Prince JD, Sellers TL, Ford WB, Talbot SR (1987) Experimental evidence for limited dispersal of Haliotid larvae (Genus Haliotis, Mollusca, Gastropoda). J Exp Mar Biol Ecol 106: 243-263

Prince JD, Sellers TL, Ford WB, Talbot SR (1988) Confirmation of a relationship between the localized abundance of breeding stock and recruitment for Haliotis rubra leach (Mollusca, Gastropoda). J Exp Mar Biol Ecol 122:91-104

Quinn GP, Keough MJ (2002) Experimental design and data analysis for biologists. Cambridge University Press, Cambridge

Saunders T, Mayfield S, Hogg A (2008) A simple, cost-effective, morphometric marker for characterising abalone populations at multiple spatial scales. Mar Freshw Res 59: $32-40$

Schnute JT, Richards LJ (1990) A unified approach to the analysis of fish growth, maturity, and survivorship data. Can J Fish Aquat Sci 47:24-40

Shepherd SA, Hearn WS (1983) Studies on Southern Australian abalone (Genus Haliotis). 4: Growth of Haliotis laevigata and Haliotis rubra. Aust J Mar Freshw Res 34: 461-475

Shepherd SA, Laws HM (1974) Studies on southern Australian abalone (genus Haliotis). II: Reproduction of 5 species. Aust J Mar Freshw Res 24:217-257

Shepherd SA, Steinberg PD (1992) Food preferences of three Australian abalone species with a review of the algal food of abalone. In: Shepherd SA, Tegner MJ, Guzman del Proo SA (eds) Abalone of the world: biology, fisheries and culture. Blackwell Scientific Publications, Oxford, p 169-181

Shepherd SA, Gruzman del Proo SA, Turrubiates J, Belmar J, Baker JL, Sluczanowski PR (1991) Growth, size at sexual maturity, and egg-per-recruit analysis of the abalone Haliotis fulgens in Baja-California. Veliger 34:324-330

Shepherd SA, Godoy C, Clarke SM (1992) Studies on southern Australian abalone (Genus Haliotis). XV: Fecundity of H. laevigata. J Malac Soc Aust 13:115-121

Editorial responsibility: Pei-Yuan Qian, Kowloon, Hong Kong, SAR
Steffani CN, Branch GM (2003) Growth rate, condition, and shell shape of Mytilus galloprovincialis: responses to wave exposure. Mar Ecol Prog Ser 246:197-209

Strathmann RR, Hughes TR, Kuris AM, Lindeman KC, Morgan SG, Pandolfi JM, Warner RR (2002) Evolution of local recruitment and its consequences for marine populations. Bull Mar Sci 70:377-396

Swain DP, Foote CJ (1999) Stocks and chameleons: the use of phenotypic variation in stock identification. Fish Res 43: $113-128$

Swain DP, Hutchings JA, Foote CJ (2005) Environmental and genetic influences on stock identification characters. In: Cadrin SX, Friedland KD, Waldmann JR (eds) Stock identification methods applications in fishery science. Elsevier Academic Press, London, p 45-85

Tarbath DB (2003) Seasonal variation in size at sexual maturity of the blacklip abalone Haliotis rubra. TAFI, Taroona

> Tegner MJ, Basch LV, Dayton PK (1996) Near extinction of an exploited marine invertebrate. Trends Ecol Evol 11: $278-280$

Temby N, Miller K, Mundy C (2007) Evidence of genetic subdivision among populations of blacklip abalone (Haliotis rubra Leach) in Tasmania. Mar Freshw Res 58:733-742

Wells FE, Keesing JK (1989) Reproduction and feeding in the abalone Haliotis roei Gray. Aust J Mar Freshw Res 40: 187-197

Wells FE, Mulvay P (1995) Good and bad fishing areas for Haliotis laevigata: a comparison of population parameters. Mar Freshw Res 46:591-598

Worthington DG, Andrew NL (1997) Does covariation between growth and reproduction compromise the use of an alternative size limit for the blacklip abalone, Haliotis rubra, in NSW, Australia? Fish Res 32:223-231

Worthington DG, Andrew NL, Hamer G (1995a) Covariation between growth and morphology suggests alternative size limits for the blacklip abalone, Haliotis rubra, in New South Wales, Australia. Fish Bull (Wash DC) 93:551-561

Worthington DG, Doherty PJ, Fowler AJ (1995b) Variation in the relationship between otolith weight and age-implications for the estimation of age of 2 tropical damselfish (Pomacentrus moluccensis and P. wardi). Can J Fish Aquat Sci 52:233-242

Submitted: January 9, 2008; Accepted: May 5, 2008

Proofs received from author(s): August 24, 2008 